\title{
Entre la movilización estudiantil y la lucha armada en Colombia. De utopías y diálogos de Paz*
}

\section{Resumen}

La actual coyuntura política en el país, marcada por las negociaciones entre el Gobierno Nacional y la guerrilla de las FARC-EP, obliga a pensar históricamente la configuración de una izquierda armada en Colombia. En tal sentido, el presente artículo se centra en la relación que tuvo un sector de la generación de estudiantes universitarios de los años sesenta y setenta del siglo XX con la lucha armada como método de participación política y de transformación social. El perfil universitario de la actual comandancia guerrillera nos condujo a reflexionar sobre las maneras como algunos activistas estudiantiles configuraron su práctica política a partir de una representación del sistema político y la apuesta por encaminar al país hacia el socialismo. Hasta cierto punto, consideramos que en la militancia universitaria de izquierdas se pueden encontrar algunas claves para comprender un presente en el que surge con fuerza la esperanza por la terminación del conflicto armado más longevo del hemisferio.

Palabras Clave: Colombia, movimiento estudiantil, guerrillas, revolución, democracia, política.

Referencia para citar este artículo: Referencia para citar este artículo: AVECEDO TARAZONA, Álvaro y SAMACÁ ALONSO, Gabriel (2015). "Entre la movilización estudiantil y la lucha armada en Colombia. De utopías y diálogos de Paz”. En Anuario de Historia Regional y de las Fronteras. 20 (2). pp. 157-182.

Fecha de recepción: 21/10/2014

Fecha de aceptación: 19/02/2015

\begin{abstract}
Álvaro Acevedo Tarazona: Profesor titular de la Universidad Industrial de Santander. Postdoctorado en Ciencias de la Educación de la Universidad Tecnológica y Pedagógica de Colombia (en curso). Doctor en Transiciones, Cambios y Permanencias en las Sociedades Modernas y Contemporáneas de Europa y América Latina de la Universidad de Huelva. Director del Grupo de Investigación "Políticas, Sociabilidades y Representaciones Histórico Educativas”. Correo electrónico: tarazona20@gmail.com.
\end{abstract}

Gabriel David Samacá Alonso: Estudiante del Doctorado en Historia del Colegio de México. Historiador y Magister en Historia de la Universidad Industrial de Santander. Integrante del Grupo de Investigación "Políticas, Sociabilidades y Representaciones Histórico Educativas". Correo electrónico: davidsalon16@ gmail.com.

\footnotetext{
* Artículo de reflexión resultado del proyecto “¿Colombia indignada?: estudiantes y movilización por la educación superior (2011-2012)", financiando por la Vicerrectoría de Investigación y Extensión de la Universidad Industrial de Santander.
} 


\title{
Between the students' movement and the armed struggle in Colombia. About utopias and Peace talks
}

\begin{abstract}
The current political situation in the country; marked by the negotiations between the Government and the guerrilla of FARC-EP, leads us into thinking of a historical configuration of an armed left-wing in Colombia. In that sense, this article focuses on the relationship that one part of a university students generation from the 60 's and 70's in the 20th century had with the armed struggle as a method of political participation and social transformation. The university profile of the current guerrilla commanders led us to reflect about the ways that some student activists configured their political fight from a representation of the political system and the commitment to lead the country towards socialism. Up to a certain point, we consider that the militancy of left-wing movements in universities is the source of some clues to understand a present when a hope for the end of the longest conflict in the hemisphere is strongly emerging.
\end{abstract}

Keywords: Colombia, student movement, guerrilla, revolution, democracy, political.

\section{Entre a mobilização estudantil e a luta armada na Colômbia. De utopias e diálogos de Paz}

\section{Resumo}

A atual conjuntura política no país, marcada pelas negociações entre o Governo Nacional e a guerrilha das FARC-EP, obriga a pensar historicamente a configuração de uma esquerda armada na Colômbia. Em tal sentido, o presente artigo centra-se na relação que teve uma parte da geração de estudantes universitários dos anos sessenta e setenta do século XX com a luta armada como metodologia de participação política e de transformação social. O perfil universitário da atual comandância guerrilheira nos levou a refletir sobre as formas em que alguns ativistas estudantis configuraram sua prática política a partir de uma representação do sistema político e a aposta por encaminhar ao país ao socialismo. Até certo ponto, consideramos que na militância universitária de esquerdas é possivel encontrar algumas chaves para compreender um presente no qual surge com força a esperança pela finalização do conflito armado mais longevo do hemisfério.

Palavras-chave: Colômbia, movimento estudantil, guerrilheiros, revolução, democracia, política. 


\section{A manera de introducción: tres episodios de nuestros días}

El 25 de marzo del año 2012 en una vivienda ubicada en la localidad de Suba, en Bogotá, fallecieron tres jóvenes universitarios luego de una explosión que además dejó como saldo tres casas con graves daños en su estructura y 51 familias vecinas afectadas. De acuerdo con las declaraciones del comandante de la Policía Metropolitana, las personas que murieron se encontraban en estado de alicoramiento y habrían manipulado entre cinco y ocho kilogramos de explosivos artesanales. Las edades de los jóvenes oscilaban entre los 19 y los 22 años; dos de ellos eran estudiantes de la Facultad de Ciencias Sociales de la Universidad Pedagógica Nacional. Otro cuerpo hallado era el de una joven egresada de ese mismo centro universitario. En el lugar de los hechos también se encontraba un herido de gravedad que estudiaba ingeniería electrónica. En referencia a esta dolorosa situación, el General Martínez no dudó en asociar los hechos a posibles vínculos subversivos o guerrilleros de los universitarios:

Esos bandidos se están aprovechando de la juventud, de la fogosidad y la inexperiencia de estos jóvenes estudiantes para hacerlos partícipes de sus actividades criminales y terroristas. Esto es un llamado a los padres de familia porque ¡cómo es posible que no sepan qué están haciendo sus hijos, dónde están sus hijos! De hecho la madre de uno de los jóvenes muertos terminó con afectaciones en su cuello y con problemas acústicos, ya que se encontraba durmiendo en el segundo piso de la casa donde ocurrió la explosión ${ }^{1}$.

Un mes después del infortunado acontecimiento, el cubrimiento de prensa dio cuenta de hallazgos en la investigación adelantada por las autoridades que confirmarían los vínculos entre la insurgencia y el activismo universitario. El mismo General Luis Eduardo Martínez aseguró a los medios que en la tercera planta de la casa "[...] fueron hallados panfletos alusivos a las FARC y a un grupo que se autodenominaba como seguidor de Jaime Bateman, el desaparecido dirigente del desmovilizado M-19"2. Esta interpretación fue reproducida por los demás medios de comunicación nacionales e incluso el sitio web del Ministerio de Educación Nacional (MEN) publicó la versión del diario El Tiempo, que se basó en un periódico local sin ningún atisbo de análisis de la situación ${ }^{3}$.

\footnotetext{
1 "Tres jóvenes universitarios murieron mientras manipulaban explosivos", en El Tiempo, Bogotá, 25 de marzo de 2012, http://www.eltiempo.com/colombia/bogota/ARTICULO-WEB-NEW_NOTA_ INTERIOR-11426321.html, consultado (18/11/2012).

2 "Estudiantes muertos en Suba estarían preparando atentado en Festival", en El Tiempo, Bogotá, 26 de abril de 2012, http://www.eltiempo.com/colombia/bogota/ARTICULO-WEB-NEW_NOTA_INTERIOR 11658122.html, consultado (18/11/2012).

${ }^{3}$ La nota de prensa difundida por el Ministerio de Educación Nacional fue tomada de El Tiempo que a su vez retomó la información del periódico gratuito llamado Mio. ver: MINISTERIO DE EDUCACIÓN NACIONAL, http://www.mineducacion.gov.co/observatorio/1722/article-303244.htm, consultado (19/11/2012). Por su parte, Caracol Radio averiguó un poco más sobre los estudiantes fallecidos, concretamente acerca de sus filiaciones con grupos e ideas de izquierda. En entrevista a un hermano de una de las víctimas fatales, se reiteró sobre los lazos entre universidad y guerrillas: "Los panfletos que encontraron de las FARC, esos todos los universitarios lo tienen, porque cada dos o tres días salen los estudiantes a repartirlo. A mi hermano le gustaba mucho el M-19 pero solo leía sobre este grupo". Ver: “QQuiénes son los tres estudiantes muertos tras explosión accidental en el noroccidente de Bogotá?”, http://
} 
Pocos días antes de lo acaecido en Suba, durante la conmemoración del 25 aniversario del asesinato del estudiante Tomás Herrera Cantillo, los alumnos de la Universidad Pedagógica y Tecnológica de Colombia (UPTC) con sede en Tunja, desarrollaron algunas actividades de protesta que culminaron en enfrentamientos con la Policía. La novedad de estos enfrentamientos entre estudiantes y fuerza pública residió en el trágico desenlace para dos estudiantes que resultaron mutilados, uno en el brazo y otro en la pierna derecha. A ellos se sumaron cinco estudiantes con heridas en el fémur, ojo derecho y pie, entre los que se encontraba una mujer. Al parecer, los estudiantes portaban en sus morrales explosivos que fueron detonados involuntariamente ocasionando las lesiones ${ }^{4}$. Un día después, uno de los heridos de gravedad perdió la vida por complicaciones en sus heridas "[...] como consecuencia de una falla en varios de sus órganos, traumas en diferentes partes de su cuerpo producto de la onda explosiva, trauma abdominal cerrado, falla respiratoria y pérdida de sangre"5.

En los últimos años, los estudiantes universitarios figuraron en las páginas de la prensa y en las emisiones de noticias de radio y televisión como víctimas fatales de hechos de violencia, ya fuese en el marco de protestas o de situaciones confusas asociadas, según las autoridades, a los posibles nexos con grupos insurgentes ${ }^{6}$. Esta hipótesis cobraría fuerza con el desarrollo de algunos hechos en los que las labores de investigación y seguimiento arrojaron como resultado la captura de jóvenes universitarios y la incautación de material explosivo en el mes de septiembre del año 2012 en el departamento de Santander.

En una finca de recreo ubicada en el municipio de Lebrija, la DIJíN encontró a un grupo de estudiantes de diferentes universidades de Cali, Bogotá, Villavicencio y Boyacá, quienes supuestamente estaban fabricando "papas bomba" para ocasionar disturbios en la Universidad Industrial de Santander (UIS). De acuerdo con la prensa local, en el allanamiento la policía encontró “[...] 136 'papas bomba' que ya estaban listas, productos químicos, teléfonos celulares, memorias USB, un computador portátil, propaganda alusiva al grupo 'Juventudes M-19', un mapa de lo que sería una universidad"7. Luego de estas capturas, la Policía Nacional asoció a algunos de

www.caracol.com.co/noticias/bogota/quienes-son-los-tres-estudiantes-muertos-tras-explosion-accidentalen-el-noroccidente-de-bogota/20120326/nota/1660284.aspx, consultado (18/11/2012).

4 "Dos estudiantes resultaron mutilados en protestas en la UPTC de Tunja", en El Tiempo, Bogotá, 20 de marzo de 2012, http://www.eltiempo.com/archivo/documento/CMS-11391147, consultado (19/11/2012).

5 "Murió estudiante tras explosión en la UPTC", en El Tiempo, Bogotá, 23 de marzo de 2012, http://www. eltiempo.com/archivo/documento/CMS-11411041, consultado (20/11/2012); "Murió estudiante que había resultado herido en la UPTC de Tunja", en El Tiempo, Bogotá, 22 de marzo de 2012, http://www.eltiempo. com/archivo/documento/CMS-11405961, consultado (19/11/2012).

${ }^{6}$ Baste recordar que en el año 2011, en el marco de las masivas movilizaciones estudiantiles en contra de la reforma a la Ley 30 de 1992, falleció un estudiante de la Universidad Santiago de Cali. Ver: "Muere estudiante por explosión en marcha estudiantil de Cali", en El Espectador, Bogotá, 12 de octubre de 2011, http://www.elespectador.com/noticias/nacional/articulo-305037-un-muerto-marcha-estudiantil-cali, consultado (16/11/2012).

7 “Con 300 'papas bomba', los 7 capturados en Lebrija querían provocar disturbios en la UIS”, en Vanguardia Liberal, Bucaramanga, 28 de septiembre de 2012, http://www.vanguardia.com/judicial/176343-con-300papas-bomba-los-7-capturados-en-lebrija-querian-provocar-disturbios-en-la-uis, consultado (21/11/2012). 
los estudiantes detenidos con hechos ocurridos en otras universidades del país, por ejemplo, la muerte de un efectivo policial en la Universidad del Valle en el mes de agosto. Los cinco jóvenes procesados, entre ellos un menor de edad y dos mujeres, fueron vinculados al Movimiento Juvenil Bolivariano y a las llamadas Juventudes del M-19, organizaciones políticas juveniles asociadas a grupos subversivos ${ }^{8}$.

Las noticias referenciadas ¿son parte de una campaña de desprestigio de los sectores de "derecha" y de los medios masivos de comunicación contra la movilización estudiantil que puso en jaque al gobierno y lo obligó a retirar un proyecto de ley en materia de educación superior? ¿Acaso confirman los posibles lazos que las guerrillas han tejido con las universidades al considerarlas escenario de reclutamiento de nuevos militantes y de desestabilización del orden público? Y los estudiantes, ¿son víctimas de su 'fogosidad' y energía, que los guerrilleros aprovechan para engrosar sus filas con incautos jóvenes que hasta ahora están buscando su identidad?, o ¿son actores estratégicos en el proyecto político de las organizaciones guerrilleras? Adelantar hipótesis o afirmaciones sobre estos hechos es prematuro. En cualquier caso, el discernimiento que interesa aquí, con miras a un análisis más ponderado, es preguntarse retrospectivamente por las razones y motivos que pueden llevar a algunos jóvenes universitarios a simpatizar e incluso integrar agrupaciones subversivas.

Esta preocupación central se ha de construir desde una mirada histórica no solo por los viejos lazos entre universidad y lucha política armada en Colombia, sino por la necesidad que surge de comprender el posible papel que ha desempeñado la movilización estudiantil en el conflicto colombiano. La formación universitaria de varios de los actuales comandantes guerrilleros de las Fuerzas Armadas Revolucionarias de Colombia-Ejército del Pueblo (FARC-EP) y del Ejército de Liberación Nacional (ELN), así como la permanencia de los mismos grupos insurgentes desde los años sesenta del siglo pasado en el país, obligan a volver la mirada para desentrañar los vasos comunicantes entre la universidad y la política. Este artículo intentará retomar las propias investigaciones de los autores sobre el tema y ciertos análisis de la historiografía nacional que aluden directa e indirectamente al papel que desempeñó la generación de los sesenta en la marcha de la vida política colombiana, cuyos efectos se sienten hoy.

\section{La generación de los años 60: del activismo estudiantil a la lucha armada}

Durante los años sesenta, Colombia experimentó un proceso de modernización en todos los órdenes, manifestado principalmente en el incremento poblacional, la urbanización creciente de sus principales ciudades y el inicio de un lento proceso de secularización de la vida cultural ${ }^{9}$. Es necesario recordar que en el año de 1958, las elites de los partidos políticos definieron un pacto conocido como el Frente Nacional (1958-1972), que la historiografía ha llamado de democracia consociacionalista, en el que se estableció una repartición del poder político desde lo local hasta lo nacional

\footnotetext{
${ }^{8}$ Ibid.

${ }^{9}$ PALACIOS, Marco, Entre la legitimidad y la violencia: Colombia 1875-1994, Bogotá, Norma, 2003, pp. $289-330$.
} 
y que cubrió no solo el ejercicio del Poder Ejecutivo sino la distribución milimétrica de la burocracia en todos los niveles del Estado. Este pacto subordinó la competencia libre por el favor del pueblo en las elecciones a una especie de ejercicio democrático, por lo menos, en los límites formales del sistema político instaurado ${ }^{10}$.

Este periodo del Frente Nacional ha tenido lecturas diferentes sobre su significado en el acontecer del país. De un lado, están quienes enfatizan en el cerramiento del sistema político y su extensión hasta 1990, variable determinante en la eclosión de la violencia contraestatal. Por otra parte, hay quienes ubican el pacto bipartidista en su momento histórico, como mecanismo finalmente efectivo para reducir y eliminar la violencia partidista, con el agravante que excluyó totalmente otras expresiones políticas ${ }^{11}$. Más allá de estas valoraciones, lo cierto es que desde finales de los años cincuenta, los estudiantes adquirieron una relevancia política, movilizándose inicialmente en apoyo al bipartidismo durante la caída de Rojas Pinilla y luego enfrentándose al establecimiento a través de la organización gremial que pronto devendría en franca lucha política ${ }^{12}$.

En 1958 se dio la primera experiencia que vinculó a ciertos grupos estudiantiles con la lucha armada a través del Movimiento Obrero Estudiantil Campesino 7 de enero (MOEC). Antonio Larrota, santandereano de nacimiento, fue la figura más reconocida de este movimiento que emergió al calor de las luchas contra el alza del trasporte en Bogotá y que con la vinculación de bandoleros como Pedro Brincos, entre otros, mutó hacia el modelo insurreccional cubano en zonas del Cauca y Urabá. Este caso dio cuenta de dos tesis que definirían a la nueva izquierda colombiana y que tendrían eco en la juventud universitaria que se formaba por aquellos días. La primera, se refiere a la desconfianza total de un sector minoritario del estudiantado en la participación electoral y, por consiguiente, la apropiación de la bandera del abstencionismo activo. La segunda, tiene que ver con la recurrencia de un sector mayoritario de los estudiantes a métodos más expeditos entre la rebeldía y la participación electoral para alcanzar las trasformaciones sociales y económicas del país. De esta forma, se instaló en la izquierda colombiana una disputa de vieja data en el amplio y abigarrado mundo de la izquierda mundial: la lucha entre el "aventurerismo" político miliciano, en abierta oposición al Estado, y el "revisionismo" de origen comunista, más cercano a la lucha política legal y paulatina ${ }^{13}$.

Herederos de una violencia partidista que tuvo sus últimos ecos hasta bien entrada la

\footnotetext{
${ }^{10}$ PÉCAUT, Daniel, Crónica de cuatro décadas de política colombiana, Bogotá, Norma, 2006, p. 39-115.

${ }^{11}$ ARCHILA, Mauricio, Idas y venidas, vueltas y revueltas: protesta social en Colombia 1958-1990, Bogotá, ICANH-CINEP, 2003.

${ }^{12}$ Para una visión general del movimiento estudiantil durante los años del Frente Nacional ver: LEAL BUITRAGO, Francisco, "La participación política de la juventud universitaria como expresión de clase", en CÁRDENAS, Martha y DÍAZ URIBE, Alberto (Eds.), Juventud y política en Colombia, Bogotá, FESCOL, 1984; LE BOT, Ivón, Educación e ideología en Colombia, Bogotá, La Carreta, 1985.

${ }^{13}$ JARAMILLO, José Abelardo, "Juventud, nueva izquierda y revolución en Colombia: Antonio Larrota González”, en Controversia, No. 194, Bogotá, CINEP, 2010, pp. 265-291; DÍAZ JARAMILLO, José Abelardo, El Movimiento Obrero Estudiantil Campesino 7 de enero y los orígenes de la nueva izquierda en Colombia 1959- 1969, Trabajo de grado para optar al título de Magíster en Historia, Bogotá, Universidad Nacional de Colombia, 2010.
} 
década de los sesenta con los remanentes de la violencia bandolera ${ }^{14}$, los nacientes grupos de la nueva izquierda no pudieron desprenderse de su historia inmediata. El Movimiento de Renovación Liberal -luego de Revolución Liberal (MRL)- fue una disidencia partidista que sirvió de aglutinante en la primera mitad de los años sesenta para diferentes sectores que no hallaban lugar en las estructuras partidistas hegemónicas. Campesinos, sectores urbanos, estudiantes y gaitanistas, confluyeron en esta agrupación que por su misma composición heteróclita, facilitó la creación y división de diferentes líneas. De la línea blanda a la dura y de esta a la radical, el MRL se convirtió en uno de los espacios políticos durante el Frente Nacional que posibilitó el agrupamiento de un sector de estudiantes que daría origen a una de las guerrillas más antiguas del mundo: el Ejército de Liberación Nacional (ELN) ${ }^{15}$.

Precisamente, la línea radical tenía estrechos vínculos con aquellos grupos de militantes del Partido Comunista que no se hallaban satisfechos con las directrices de Moscú. Esta "disidencia de la disidencia" se agrupó alrededor del semanario Vanguardia del MRL y llegó a tener en sus filas a futuros dirigentes del ELN como Fabio y Manuel Vásquez Castaño, Víctor Medina Morón y Francisco Caraballo, futuro líder del Ejército Popular de Liberación (EPL) ${ }^{16}$. En la tendencia más inclinada hacia la izquierda dentro del MRL confluyeron no solo jóvenes inquietos por el contexto mundial, especialmente por el influjo de la Revolución Cubana, sino que también fueron plataforma para las demandas agraristas de líderes como Juan de la Cruz Varela, los viviendistas de la Costa Atlántica y de Cali liderados por Alfonso Berberena y los exguerrilleros liberales de Santander, Caldas y los Llanos Orientales ${ }^{17}$. En el seno del MRL se incubó el contraste entre la concepción legalista de la revolución, encabezada por Alfonso López Michelsen, y una más amplia que consideraba al régimen como excluyente y oligárquico y lanzaba vítores al "Capitán Fidel Castro" hasta posicionar la idea de la dependencia de la economía colombiana respecto al capital norteamericano ${ }^{18}$.

Con el MRL hubo entonces un nuevo espacio más institucionalizado en el que diferentes sectores, entre ellos, los estudiantes universitarios junto con otros actores sociales, emergieron a la vida política durante los años sesenta. En su interior, pero no

\footnotetext{
${ }^{14}$ Una cronología sobre el llamado periodo de La Violencia la ofrece Marco Palacios. PALACIOS, Marco, Entre la legitimidad y la violencia, pp. 289-330.

${ }^{15}$ AYALA DIAGO, César Augusto, Resistencia y oposición al establecimiento del Frente Nacional: los orígenes de la Alianza Nacional Popular, ANAPO. Colombia, 1953-1964, Bogotá, Universidad Nacional de Colombia, 1996, pp. 83-85. El clásico libro de Alejo Vargas da cuenta de esto en el caso del ELN y sus relaciones con las guerrillas liberales de Rafael Rangel y el papel de las Juventudes del MRL. Ver: VARGAS VELÁSQUEZ, Alejo, Colonización y conflicto armado: Magdalena Medio Santandereano, Bogotá, CINEP, 1992, pp. 91-217.

${ }^{16}$ CHILD, Jorge, "El MRL”, en GALLÓn, Gustavo y BETANCUR, Mónica, Entre movimientos y caudillos: 50 años de bipartidismo, izquierda y alternativas populares en Colombia, Bogotá, CINEPCEREC, 1989, pp. 68-90.

17 VARGAS, Alejo, Política y armas al inicio del Frente Nacional, Bogotá, Universidad Nacional de Colombia, 1996, pp. 155-159.

${ }^{18}$ AYALA DIAGO, César, "El origen del MRL (1957-1960) y su conversión en disidencia radical del liberalismo colombiano", en Anuario de Historia Social y de la Cultura, No. 22, Bogotá, Universidad Nacional de Colombia, 1995, pp. 95-121.
} 
solo allí, comenzaron a circular y a posicionarse algunas ideas fuerza, que marcaron profundamente a los jóvenes de izquierda que optarían por la lucha armada. A partir de la apropiación del marxismo en sus vertientes soviética y china principalmente, los estudiantes y casi toda la izquierda apuntaló la idea de un régimen excluyente, controlado por la "oligarquía", que no podía ser reformado por la vía pacífica. En economía, se retomaron discusiones de los años treinta acerca de la dependencia, la injusta división internacional del trabajo y la explotación de los recursos naturales ${ }^{19}$.

Al respecto, Marco Palacios sostiene sin ambages, cómo las universidades fueron el nicho natural de emergencia de toda una tendencia político-militar que cobró relevancia en los años sesenta: la corriente de liberación nacional adscrita a las tesis del foquismo guerrillero ${ }^{20}$. La experiencia en las luchas contra Abadía Méndez a finales de los años veinte, la condición de víctimas de la represión de la dictadura en 1954 que generó la muerte de más de una decena de estudiantes y el papel cumplido en la caída de Rojas Pinilla en 1957, constituía el capital político de los estudiantes durante la primera mitad del siglo XX en las luchas libradas en las calles ${ }^{21}$. Los estudiantes colombianos gozaban de un prestigio político y social en los albores de los años sesenta que les granjeó cierto respaldo social a sus reivindicaciones gremiales. No obstante, fue la articulación con las alas juveniles de los movimientos de oposición política, inicialmente el Partido Comunista Colombiano (PCC) y el MRL, lo que generó la cooptación de algunos líderes de varias universidades para que se diera el salto hacia la creación de grupos guerrilleros ${ }^{22}$.

De todas las agrupaciones insurgentes del país, la que más se nutrió desde sus inicios del contingente de jóvenes universitarios fue el ELN. La conformación de la famosa Brigada Pro Liberación José Antonio Galán, adiestrada militarmente en Cuba por petición de los estudiantes colombianos, estuvo integrada entre otros universitarios por Víctor Medina Morón, exdirigente estudiantil de la Universidad Industrial de Santander (UIS) y miembro de las Juventudes MRL, y Ricardo Lara Parada, también estudiante de Ingeniería Química durante tres semestres en la UIS y miembro de la misma organización política a la que pertenecía Medina Morón ${ }^{23}$. El vínculo de la Asociación Universitaria de Santander (AUDESA) con la creación del ELN

\footnotetext{
${ }^{19}$ GÓMEZ GARCÍA, Juan Guillermo, Cultura intelectual de resistencia: contribución a la historia del "libro de izquierda". Medellín en los años setenta, Bogotá, Desde Abajo-Colciencias-Universidad de Antioquia, 2005.

${ }^{20}$ PALACIOS, Marco, Violencia pública en Colombia 1958-2010, Bogotá, Fondo de Cultura Económica, 2012, p. 79.

${ }^{21}$ Un abordaje interesante sobre la trayectoria política del estudiantado durante la primera mitad del siglo XX puede verse en JARAMILLO DÍAZ, José Abelardo, "El 8 de junio y las disputas por la memoria, 19291954”, en Historia y Sociedad, No. 22, Medellín, Universidad Nacional de Colombia, 2012, pp. 157-189.

22 PALACIOS, Marco. Violencia pública en Colombia 1958-2010..., Op. cit., pp. 80-81.

${ }^{23}$ ARENAS REYES, Jaime, La guerrilla por dentro: análisis del ELN colombiano, Bogotá, Tercer Mundo, 1971, p. 16. Para un esbozo biográfico sobre Lara Parada ver la entrevista que le concedió a Óscar Castaño: LARA PARADA, Ricardo, El guerrillero y el político: conversación con Óscar Castaño, Bogotá, Oveja Negra, 1984, pp. 37-66.
} 
es suficientemente conocido como para repetirlo ${ }^{24}$. Ahora, lo que interesa poner de presente es la concepción ideológica y política que imperó en una gran cantidad de jóvenes universitarios en los años sesenta y setenta que condujo a algunos de ellos a la toma de las armas. Sobre esta elección, se retomará el caso curiosamente más olvidado por la izquierda y la derecha colombiana: Jaime Arenas Reyes, un líder estudiantil de suma importancia ${ }^{25}$.

En una entrevista concedida al periodista Germán Castro Caycedo en octubre de 1969, el exestudiante de Ingeniería Industrial, anteriormente líder universitario de talla nacional y desertor del ELN, Jaime Arenas Reyes, evidenció cómo una generación asumió como su destino inexorable, el levantamiento en armas para la implementación de un proyecto de liberación nacional.

Las primeras experiencias políticas de Arenas, tanto en el colegio como en la universidad, alcanzaron a tener un cariz democrático. Además de haber hecho parte de los Consejos Estudiantiles y gestionado mejoras socioeconómicas a través del diálogo con las autoridades universitarias, llegó a ser elegido representante estudiantil como corolario de su liderazgo en la UIS. En la medida en que las luchas universitarias fueron radicalizándose, al tiempo que se fraguó en una organización más autónoma e ideologizada como la Federación Universitaria Nacional (FUN), el giro hacia la izquierda se consumó ${ }^{26}$. Este proceso fue visible en algunas protestas estudiantiles de 1962 y se concretó en la organización y desarrollo de una huelga que duró varios meses durante el año 1964 que culminó con la primera marcha estudiantil universitaria desde Bucaramanga hasta Bogotá. La marcha se realizó con el fin de solicitarle al gobierno nacional el reintegro de algunos estudiantes expulsados de la UIS, una educación pública de alta calidad con base en un sistema nacional universitario propio y la defensa de la autonomía universitaria. Jaime Arenas fue la gran figura de esta movilización contra el rector Juan Francisco Villarreal. En razón del liderazgo y activismo que debió desplegar en la población y los medios de comunicación y a pesar de no haber marchado los más de 400 kilómetros a pie, Jaime Arenas Reyes, junto con sus compañeros, fue escuchado en el Capitolio Nacional con un discurso memorable en el que avizoraba los principales problemas que afectaban a la educación superior en Colombia $^{27}$.

\footnotetext{
${ }^{24}$ ACEVEDO TARAZONA, Álvaro, Modernización, conflicto y violencia en la universidad en Colombia: AUDESA, 1953-1984, Bucaramanga, UIS, 2004; MEDINA GALLEGO, Carlos, FARC-EP y ELN: una historia política comparada 1958-2006, Trabajo de grado presentado para optar por el título de Doctor en Historia, Bogotá, Universidad Nacional de Colombia, 2010.

${ }^{25}$ La apreciación de "líder estudiantil colombiano más importante del siglo XX" fue compartida por varias personas de su generación. También nos basamos en la valoración que hizo Enrique Santos Calderón en el prólogo de la reedición del libro La guerrilla por dentro, que reprodujo una columna de abril de 1971 luego de la muerte de Arenas. Ver: SANTOS CALDERÓN, Enrique, "Prólogo. Un libro premonitorio", en ARENAS REYES, Jaime, La guerrilla por dentro, Bogotá, Intermedio, 2009, pp. 11-14.

${ }^{26}$ RUÍZ MONTEALEGRE, Manuel, Sueños y realidades: procesos de organización estudiantil 1954-1966, Bogotá, Universidad Nacional de Colombia, 2002.

27 ACEVEDO TARAZONA, Álvaro, "La marcha de los estudiantes de la UIS, 1964: símbolo del movimiento estudiantil colombiano", en Revista Historia de la Educación Colombiana, No. 12, Pasto, Universidad de Nariño, 2009; ARENAS REYES, Jaime, "Palabras del señor Jaime Arenas Reyes, estudiante de la Universidad Industrial de Santander 1964", en BARRIENTOS ARANGO, José, La Asociación
} 
El reconocimiento obtenido por su papel en las luchas estudiantiles en la UIS se tradujo en una carrera ascendente en el campo universitario al ser delegado para eventos nacionales e internacionales de estudiantes, creador de la FUN, presidente de su II Congreso Nacional y secretario electo de la Unión Internacional de Estudiantes con sede en Praga. Combinó su activismo estudiantil con la vida política fuera de las aulas universitarias, en las filas de las juventudes del MRL. Alcanzó a ser miembro del directorio departamental y municipal del movimiento y candidato al Concejo de Bucaramanga. El mismo Arenas reconoció, en una entrevista a Castro Caycedo, que fue la salida de la universidad la que le permitió conocer otras problemáticas y relacionarse con sectores obreros y populares. De esta manera, se alejó paulatinamente de las lides estudiantiles y se radicalizó políticamente al entrar en contacto con problemáticas sociales más amplias, dejando a un lado su formación universitaria, debido a la expulsión que sufrió de la UIS por bajo promedio académico ${ }^{28}$.

Para Arenas, la alternancia entre la lucha gremial y política tuvo su mayor despliegue antes de incorporarse formalmente a la guerrilla del ELN en las filas del Frente Unido del Pueblo, junto al sacerdote y luego guerrillero Camilo Torres Restrepo. La organización de las bases populares y las labores de agitación realizadas junto a Camilo, con el fin de crear un anti Frente Nacional, lo posicionaron como una de las figuras más importantes de la nueva izquierda colombiana. Tras entrar en contacto con otros líderes universitarios como Galo Burbano y Julio César Cortés, Jaime Arenas se involucró de lleno en la creación política del ELN. Así pues, para 1965 Jaime Arenas Reyes se había convertido en un exlíder universitario dedicado tiempo completo a la actividad política como acompañante de Camilo Torres y enlace de este con el ELN. Luego de la ida al monte del cura rebelde a finales de ese año de 1965 y su posterior muerte en combate en febrero de 1966, Jaime Arenas se vio obligado a pasar a la clandestinidad ${ }^{29}$.

Una de las dimensiones menos exploradas en el periplo de esta generación de jóvenes universitarios que optó por la vida guerrillera tiene que ver con los efectos que tales decisiones trajeron no solo a la vida política nacional sino a las familias que sufrieron y vivieron la ida de un ser querido a la lucha armada. Al parecer, una variable que coadyuvó a esta situación, especialmente en las filas del ELN y del EPL, fue la mística de la que se sentían portadores los universitarios convertidos en guerrilleros. Tal y como lo ha analizado Roberto Sancho, el ELN resulta un caso significativo de sacralización de la política. A partir de fundamentos cristianos, la militancia se asumió como un apostolado cuya capacidad de sacrificio era total, con el fin de redimir a los

Colombiana de Universidades, 25 años de historia (1958-1983), Bogotá, Gráficas Carmán, 1983, pp. 147153. Y entrevista a OLARTE PERALTA, Mario, Bucaramanga, noviembre 10 de 1999.

${ }^{28}$ CASTRO CAYCEDO, Germán, Del ELN al M-19: once años de lucha guerrillera, Bogotá, Carlos Valencia Editores, 1980, pp. 7-52.

${ }^{29}$ Sobre Camilo Torres pueden consultarse las dos obras más conocidas que todavía no han sido superadas por la historiografía colombiana y que dan cuenta de las relaciones de Arenas con Camilo y la configuración del Frente Unido: BRODERICK, Walter, Camilo Torres: el cura guerrillero, Bogotá, Círculo de Lectores, 1977; VILLANUEVA, Orlando, Camilo: acción y Utopía, Bogotá, Universidad Nacional de Colombia, 1995. 
pobres de la tierra. Con razón, la consigna de Camilo Torres aludía a la entrega "hasta las últimas consecuencias". En el ELN, esta decisión hasta el límite se reconoce en el grito comunero-religioso de "Ni un paso atrás, liberación o muerte" 30 .

En el caso del ELN, el estrecho vínculo entre política y militancia religiosa, en el marco de los cambios que experimentó la Iglesia Católica en los años del Concilio Vaticano II y la Conferencia Episcopal Latinoamericana de Medellín, explica en parte la vinculación de varios religiosos a la lucha guerrillera. Además de los renombrados casos de los sacerdotes españoles Manuel Pérez Martínez, Domingo Laín Sáenz y José Antonio Jiménez, es necesario evocar el caso de Leonor Esguerra, religiosa y rectora del famoso Colegio Marymount, quien llegó a militar en el ELN. La concepción de la lucha por los pobres de la tierra y la misma idea de sacrificio total por el pueblo que dominó el pensamiento de los religiosos militantes, fue compartida por los estudiantes de esta generación ${ }^{31}$.

¿Qué pensaban los estudiantes que decidieron irse un día para el monte a luchar por una utopía en la que algunos de ellos perecieron por las balas, incluso de sus propios compañeros de armas? Una posible respuesta se puede encontrar en las palabras del mismo Arenas cuando se refirió al tema en las cartas de despedida que le dejó a sus familiares, esposa e hijas:

No me despedí de ella por falta de tiempo y porque consideraba muy duro el adiós. No quería llevarme un recuerdo triste para la guerrilla. A ella y a mis padres que estaban en Medellín, les envié cartas similares: la necesidad de la lucha hace que deba irme a las montañas, pues en la ciudad me resulta muy difícil ya hacer algún papel positivo a favor de la revolución. No se preocupen por mí. He tomado la determinación conscientemente. Si muero será por un ideal que es el mismo que ha guiado toda mi vida [...] Es para mí tremendo causarles este dolor, pero las ideas son más fuertes que los sentimientos ${ }^{32}$.

Este breve testimonio da cuenta del conjunto de razones que llevaron a Arenas y a varios de su generación a tomar una decisión tan radical. La entrega total a un ideal en el que se antepuso lo ideológico a la misma situación emocional personal o la necesidad de irse a la montaña con una imagen que no los golpease anímicamente, fueron dos de los elementos íntimos que posibilitaron la creación de los grupos guerrilleros en Colombia. El joven en tránsito de ser guerrillero consideraba como algo cierto y factible el logro en el corto plazo de la revolución, meta a la que se comprometía con su esfuerzo individual consciente, no como resultado de una manipulación. Un

\footnotetext{
30 SANCHO LARRAÑAGA, Roberto, "Discurso ideológico y religión política en la izquierda revolucionaria: reconfiguración de lo sagrado en los años sesenta del siglo XX”, en ACUÑA RODRÍGUEZ, Olga Yanet y GUERRERO BARÓN, Javier (Comp.), Para reescribir el siglo XX: memoria, insurgencia, paramilitarismo y narcotráfico, Medellín, La Carreta-UPTC, 2011, pp. 207-232.

${ }^{31}$ CLAUX CLARRIQUIRY, Inés, La búsqueda: testimonio de Leonor Esguerra, Medellín, Pregón, 2001; RESTREPO, Javier Darío, La revolución de las sotanas: Golconda 25 años después, Bogotá, Planeta, 1995; ARREGI, Ión, "El cura Pérez”: los sueños intactos, Madrid, Tercera Prensa-Hirugarren Prentsa, 1998.

${ }^{32}$ CASTRO CAYCEDO, Germán. Del ELN al M-19: once años de lucha guerrillera ..., p. 28.
} 
hombre nuevo entregado en cuerpo y alma a la revolución estaba dispuesto a ofrendar la vida, si fuese necesario, para alcanzar la utopía igualitaria y la justicia social.

El diagnóstico sobre el estado de cosas a nivel político y económico de la nación y el mundo y la valoración del compromiso absoluto con un proyecto estaba tamizado en una valoración positiva, o por lo menos necesaria, del uso la violencia en la política. Esto se acompasaba con una idea sobre la muerte en la que llegado el caso, morir era una forma de dar la vida por la causa. Los mismos guerrilleros cayeron presos de un imaginario heroico en el que sustituyeron los prohombres de la "oligarquía" por sus propios personajes: Camilo Torres Restrepo sería uno de los primeros "santos" que ingresaría en el panteón eleno ${ }^{33}$.

Es bien sabido el destino fatal de muchos de los estudiantes e intelectuales en los primeros años de lucha del ELN. Lo paradójico es que algunos de ellos fueron fusilados por sus propios compañeros de lucha, luego de unos consejos verbales de guerra en los que predominó la desconfianza en el interior de las filas hacia los jóvenes citadinos y las disputas por el mando en la organización. Este fue el caso de Víctor Medina y Julio César Cortés, entre otros. En el fondo de esta situación se puede inferir una profunda contradicción entre el mundo rural y urbano en un país que se estaba modernizando a marchas forzadas. También emergió con fuerza una tradición guerrerista y campesina que puede remontarse incluso hasta las guerras civiles del siglo XIX, pero que con certeza hundía sus raíces en la reciente violencia partidista en la que el poder de las armas se anteponía a cualquier "devaneo" intelectual de unos muchachos que no conocían la cruda realidad. El mismo Arenas recordaba cómo este contraste entre la ciudad y el campo puso en desventaja a los noveles guerrilleros:

La adaptación del estudiante a la vida del monte es generalmente lenta, difícil, penosa. Es necesario comenzar por saberse defender en la selva. Acostumbrarse a caminar en ella es una de las cosas más demoradas, porque se trata de aprender a descargar el pie al caminar, saberlo afirmar para bajar precipicios o escalar pendientes altas. En una palabra, la lucha inicial es por conseguir una buena agilidad del cuerpo, lo que para el hombre de la ciudad no es fácil [...] En la montaña se lee poco, pues el interés por los libros es escaso dentro de la mayoría del personal: campesinos que han aprendido a leer y escribir en las filas y lo hacen con mucha dificultad. La guerrilla es fundamentalmente campesina; el número de estudiantes es bastante escaso en ella. En la actualidad, con Fabio Vásquez Castaño hay solamente cuatro estudiantes -bueno, hasta cuando me vine, en febrero- ${ }^{34}$.

Una realidad paradójica de esta guerrilla de primera generación, como la llama Eduardo Pizarro Leongómez, es la importante relación que estableció con el mundo universitario y el trágico desenlace político y militar que vivieron varios de sus

\footnotetext{
${ }^{33}$ En los procesos de iconización, la figura de Ernesto Guevara es quizá el mejor ejemplo para el caso latinoamericano. Tras la muerte de "Manuel Marulanda", "Alfonso Cano" o el "Mono Jojoy", las FARC-EP han desarrollado un proceso similar con sus figuras. Una mirada general al caso del Ché Guevara se puede ver en LÓPEZ, Luis y ZIFF, Trisha, Chevolution, México, 2008.

${ }^{34}$ CASTRO CAYCEDO, Germán. Del ELN al M-19: once años de lucha guerrillera ..., pp. 34-35.
} 
miembros más destacados. En parte, ello se debía a la desconfianza no solo frente a los intelectuales sino a los estudiantes como tal, como el mismo Camilo Torres lo expresó en su conocido Mensaje a los Estudiantes, solo una minoría muy comprometida y consciente podía superar las tentaciones pequeñoburguesas para "ascender al pueblo"35. La idea de los estudiantes como un grupo "pequeñoburgués" que no podía ser la vanguardia de la revolución haría carrera en la izquierda colombiana. Los nombres de Víctor Medina Morón, Julio César Cortés y Heliodoro Ochoa, fueron solo tres de los fusilados por la misma organización, hechos que sirven de señal para conocer el destino que tuvo una generación de hombres y mujeres jóvenes que apostaron llegar al poder por medio de las armas.

A diferencia del ELN, las FARC-EP, fundadas entre 1964 y 1966, no tuvieron origen en ninguna universidad, lo que no significa que en su historia no haya habido relaciones con los estudiantes. Estudiosos como Eduardo Pizarro han recordado que la relación entre las FARC y el PCC, y con ella la posible vinculación de militantes de la Juventud Comunista a la lucha armada, estuvo mediada por el carácter profundamente agrarista y de autodefensa de esa agrupación en sus inicios. Entre los años sesenta y ochenta, las FARC decidieron mantener una posición defensiva, centrada en las directrices del PCC y con un crecimiento muy lento de sus militantes armados ${ }^{36}$.

A pesar de esta táctica, el llamado a los estudiantes como un sector progresista que podía unirse a sus filas se mantuvo en todas las guerrillas colombianas. En el caso de las FARC, la situación cambiaría desde mediados de los años ochenta cuando comenzaron a implementarse las decisiones de la VIII Conferencia en el marco del genocidio político contra la Unión Patriótica y el carácter ofensivo que asumió la nueva estrategia político-militar ${ }^{37}$. ¿Qué sucedió en la relación entre activismo estudiantil y la lucha armada en los años setenta cuando el movimiento estudiantil experimentó, a principios de esta década, un resurgimiento? ¿Cómo se desarrolló la relación entre la lucha gremial y la lucha política, incluso la armada durante estos años?

\section{El predominio de la lucha política sobre lo gremial: la mistificación de la lucha armada en los años setenta}

Entre 1971 y 1972, el movimiento estudiantil experimentó un nuevo auge de las luchas y movilizaciones que, para la Universidad Nacional de Colombia en Bogotá y la Universidad de Antioquia, terminaron en la consecución del cogobierno ${ }^{38}$. En este contexto, tal y como lo sugiere Jorge Cote, las demandas estudiantiles por autonomía, defensa de la educación pública y en contra de la intervención extranjera en la definición de la política investigativa y educativa, estuvieron determinadas por

\footnotetext{
35 TORRES RESTREPO, Camilo, Escritos escogidos 1966-1986, Tomo II, Bogotá, Cimarrón Editores, 1986, pp. 551-553.

${ }^{36}$ PIZARRO LEONGÓMEZ, Eduardo, Las FARC (1949-2011): de guerrilla campesina a máquina de guerra, Bogotá, Norma, 2011.

${ }^{37}$ PÉCAUT, Daniel, Las FARC: ¿una guerrilla sin fin o sin fines?, Bogotá, Norma, 2008, pp. 105-131.

${ }^{38}$ ARCHILA, Mauricio, "El movimiento estudiantil en Colombia: una mirada histórica", en Revista del Observatorio Social de América Latina, No. 31, Buenos Aires, Clacso, 2012, pp. 78-84.
} 
la militancia política de izquierdas de la gran mayoría de estudiantes interesados en estas cuestiones $^{39}$. Los hechos de represión de los que fueron víctimas los estudiantes desde finales de la década anterior, que condujeron a la ilegalización de la FUN por parte del presidente Lleras Restrepo, o los acontecimientos luctuosos de febrero de 1971 en Cali, que desembocaron en la muerte de varios estudiantes, ayudaron a que un sector minoritario de los universitarios sobredimensionara desde varios referentes ideológicos la lucha armada ${ }^{40}$.

A diferencia de la década anterior en la que el castro-guevarismo fue la tendencia ideológica que contó con el mayor apoyo en el ámbito universitario, con alguna influencia de los postulados de la Revolución China en pleno diferendo con la Unión de Repúblicas Socialistas Soviéticas (URSS), los años setenta presenciaron el dominio de las corrientes del maoísmo en las principales universidades, estas corrientes también tuvieron relaciones con la lucha armada. Por aquellos años había tomado forma lo que Mauricio Archila llama el "campo ML", denominación que aludía al conjunto de organizaciones marxistas-leninistas afines al proceso revolucionario chino, cada cual autoconcebida más radical que sus pares.

Este campo se conformó, por lo menos, por tres tendencias y configuró un espectro ideológico que exacerbó las recriminaciones entre los diferentes grupos. En la "derecha" del maoísmo colombiano es posible ubicar a la Juventud Patriótica, organización juvenil del recién fundado Movimiento Obrero Independiente Revolucionario (MOIR-1969), que alcanzó a tener el control de las instancias representativas en las principales universidades del país. En el "centro" se encontró una miríada de grupúsculos que se reclamaban más radicales que la Juventud Patriótica (JUPA), entre estos se destacaron los llamados Grupos Marxistas-Leninistas (ML), la Liga Marxista Leninista de Colombia (Liga ML), la Corriente Marxista Leninista (CML) que aglutinó a la Unión Proletaria (UP), el Núcleo Marxista Leninista (NML) y la Unión Comunista Revolucionaria (UCR). Finalmente, como parte de la escisión con el PCC, se dio la creación del Partido Comunista Marxista Leninista (PC-ML) que tuvo su brazo armado, el EPL. Desde luego, esta era la tendencia más radical y combativa ${ }^{41}$. Independientemente de las diferencias políticas e ideológicas existentes en el campo marxista-leninista, interesa destacar que todas las organizaciones compartieron la desconfianza hacia la democracia como sistema político y se plantearon la

\footnotetext{
39 COTE RODRÍGUEZ, Jorge, "El movimiento estudiantil de 1971: entre la homogeneidad y la heterogeneidad", en ARCHILA, Mauricio, Una historia inconclusa: izquierdas politicas y sociales en Colombia, Bogotá, CINEP, 2009, pp. 413-462.

${ }^{40}$ Ibid. Para los hechos de Cali ver: HERRERA, Vianney y TRUJILLO, Leonor, Movimiento estudiantilUniversidad del Valle-1971: como fuerza social y su influencia histórica, Cali, Universidad del Valle, 1993. Sobre los acontecimientos que condujeron al cierre de la FUN ver la evocación de MORENO DURÁN, R.H, "La memoria irreconciliable de los justos: la Universidad Nacional en la década de los 60", en Análisis Político, No. 7, 1989, pp. 77-87.

${ }^{41}$ ARCHILA, Mauricio, "El maoísmo en Colombia: la enfermedad juvenil del marxismo-leninismo", en Controversia, No. 190, Bogotá, CINEP, 2008, pp. 156-158; MOLANO, Frank, "La izquierda maoísta colombiana: organizaciones y mentalidades en la década de 1970", en ACUÑA RODRÍGUEZ, Olga Yanet y GUERRERO BARÓN, Javier (Comp.), Para reescribir el siglo XX: memoria, insurgencia, paramilitarismo y narcotráfico, Medellín, La Carreta-UPTC, 2011, p. 358.
} 
construcción del socialismo para Colombia a través de varias estrategias, incluida la lucha $\operatorname{armada}^{42}$. Al igual que los otros líderes estudiantiles de la época, por citar un caso, Pedro León Arboleda inició su activismo desde sus últimos años de colegio, situación que le granjeó la expulsión del seminario de Sincelejo para luego ingresar a la Universidad de Antioquia a cursar estudios de Filosofía y Letras. Allí desplegó sus capacidades literarias y se vinculó a periódicos que lo llevaron al sindicalismo en este ramo y, progresivamente, a distanciarse del Partido Comunista. Su militancia sindical lo llevó a formar, junto con personajes como Pedro Vásquez Rendón y Francisco Garnica, el PC-ML y a insertarse en la lucha armada de manera efectiva hasta su muerte a mediados de los años setenta ${ }^{43}$. Situaciones similares se encuentran en personajes relevantes para la historia del maoísmo en Colombia como el fundador del MOIR, el santandereano Francisco Mosquera, quien también pasó por la universidad y se vinculó al sindicalismo, aunque sin ingresar a ninguna guerrilla. Caso diferente fue el del conocido líder del EPL y exmilitante de las JMRL, Francisco Caraballo ${ }^{44}$.

La entronización de la lucha armada en el campo maoísta se diferenció del modelo insurreccional por haber adherido las tesis de la guerra popular prolongada y con ello la sujeción de lo militar a lo ideológico-político. El purismo doctrinario de todos los grupos maoístas llevó a la mistificación de la lucha guerrillera. Una parte de esta generación radicalizada no reconoció adscripción política alguna y sintió en la empuñadura de las armas el más alto grado de compromiso con el pueblo. Los activistas y vanguardias de izquierda se sentían los conductores de la humanidad hacia paraísos de cucaña y miel, para lo cual las bases estaban obligadas a seguir la verdad revelada contenida en las cartillas del marxismo-leninismo. El mesianismo implícito en estos nuevos iluminados posicionó la ida al campo o a las comunidades empobrecidas, primero, para lavar los devaneos y pecados "pequeñoburgueses" de la mayoría de universitarios; y segundo, para ir a vivir con y como el pueblo, sin descontar todos los sufrimientos y librar todas las luchas, incluyendo las interiores ${ }^{45}$. La fluida relación entre la lucha política estudiantil y la opción de las armas que en los años sesenta fue una novedad, una década más tarde sería vista como una relación legítima y natural por los estudiantes comprometidos con la radicalización de la lucha.

\footnotetext{
${ }^{42}$ En un reciente ensayo, Isidro Vanegas llama la atención sobre la forma como las diferentes guerrillas han desconfiado de los mecanismos de participación política de la democracia y, en general, de los fundamentos del sistema político mismo. Para el autor, las guerrillas hicieron parte de un movimiento de desprecio por la democracia impulsado por algunos intelectuales que legitimaron el uso de la violencia revolucionaria como parte de la nueva historia del país. En todo caso, las fallas de la democracia o su carencia absoluta sirvieron de acicate para justificar el alzamiento armado. Ver: VANEGAS USECHE, Isidro, "Las guerrillas, la democracia y el Frente Nacional", en CABALLERO ARGAEZ, Carlos, PACHÓN BUITRAGO, Mónica y POSADA CARBÓ, Eduardo (Comps.), Cincuenta años de regreso a la democracia: nuevas miradas a la relevancia histórica del Frente Nacional, Bogotá, Uniandes, 2012, pp. 187-203.

${ }^{43}$ VILLARRAGA, Álvaro, PLAZAS, Nelson, Para reconstruir los sueños: una historia del EPL, Bogotá, Fundación Progresar, 1994, pp. 11-107; CALVO OCAMPO, Fabiola, EPL:diez hombres, un ejército, una historia, Bogotá, ECOE, 1985.

${ }^{44}$ DÍAZ JARAMILLO, José Abelardo, "Del liberalismo al maoísmo: encuentros y desencuentros políticos en Francisco Mosquera Sánchez, 1958-1969”, en Anuario Colombiano de Historia Social y de la Cultura, Vol. 38, Bogotá, Universidad Nacional de Colombia, 2000, pp. 141-176.

${ }^{45}$ ARCHILA, Mauricio. "El maoísmo en Colombia: la enfermedad juvenil...", pp. 156-158; MOLANO, Frank. "La izquierda maoísta colombiana: organizaciones y mentalidades...".
} 
Una organización como el MOIR llegó a defender inicialmente el camino de la lucha armada como una de las formas viables para conseguir los cambios estructurales de la sociedad colombiana. Su fundador, Francisco Mosquera, consideraba que toda revolución verdadera había sido producto de la violencia revolucionaria. De manera similar a Camilo Torres Restrepo antes de alistarse en las filas del ELN, Mosquera responsabilizó a las "clases dominantes intermediarias del imperialismo" por el uso de la violencia por parte del proletariado, pues aquellas no daban muestras de ceder sus posiciones de poder y privilegios por medios pacíficos. Por esta razón, consideraba que la guerra popular era la máxima expresión de la agudización de la lucha de clases, aunque hacía la salvedad que la conducción de la lucha armada debía estar bajo el mando político. En sus propias palabras:

[...] son dos las vías: o se rompe el orden institucional de los burgueses y terratenientes proimperialistas, que es la vía de la Comuna de París, de la revolución bolchevique rusa, la revolución china y otras revoluciones; [o se] "observan las normas de la democracia burguesa", que es la vía por la que abogan Allende y los partidos que en coalición gobiernan en Chile, principalmente el revisionista Partido Comunista de Chile, así como los oportunistas de derecha de todo el mundo ${ }^{46}$.

En el marco de la coyuntura universitaria de 1971-1972, se dio una tajante diferenciación entre los partidarios de emprender un proceso de organización de masas que desembocaría en la creación de una organización nacional estudiantil y aquellos que optaron por acciones directas para combatir la represión oficial ante la imposibilidad de conseguir cambios parciales en un sistema que debería derrumbarse por completo. La Juventud Comunista (brazo juvenil del PCC) deploró, como buena organización leninista, cualquier acto violento radical emotivo a partir de epítetos como "extremoizquierdista", "guerrillerista" e "infantilismo de izquierda" 47 . Aunque la JUPA no expresó un compromiso efectivo con la lucha armada, la batería de argumentos que emplearon en aquellos años, confirmaba una oposición total al régimen; para tal efecto, reivindicó las acciones de masas en oposición al "fascismo" y al "imperialismo". La defensa a ultranza de las masas populares, la legitimación de la violencia revolucionaria para oponerse a la violencia reaccionaria -como rezaba una consigna de la época- y la convicción de caminar en el proceso de una revolución colombiana, fueron tres ideas compartidas en mayor o menor grado por los estudiantes radicales colombianos de aquella época ${ }^{48}$.

\footnotetext{
${ }^{46}$ VALVERDE, Umberto, Colombia: tres vías a la revolución, Bogotá, Círculo Rojo Editores, 1973, pp. 145. En otra respuesta, Mosquera reconocía sin ambages cómo el MOIR, por lo menos para 1973, era partidario de la lucha del EPL: "[...] la lucha guerrillera no es una forma de lucha más simplemente para responder a las represiones oficiales en ciertas regiones del país. El proletariado debe crear los núcleos guerrilleros, y en base de estos conformar el ejército popular de liberación, y este a su vez, coronará la liberación nacional del yugo del imperialismo norteamericano", en VALVERDE, Umberto, Colombia: tres vías a la revolución, p. 145.

${ }^{47}$ Para consultar sobre la posición de la JUCO, se pueden revisar: CAICEDO TURRIAGO, Jaime, "Movimiento juvenil, movimiento estudiantil y unidad popular", en PUIG, Julio y ZULUAGA, Olga (Comps.), Documentos teóricos internos al movimiento estudiantil 1971, Medellín, Universidad de Antioquia, 1974, pp. 235-236; POSADA, Leonardo, "Constancia ante el Comité de Solidaridad", en PUIG, Julio y ZULUAGA, Olga (Comp.), Documentos teóricos internos..., pp. 53-54.

48 TORRES, Marcelo, "Discurso de Marcelo Torres ante el Consejo Nacional de Rectores", http://
} 
Quienes pasaron a la lucha clandestina, ya fuese en la militancia urbana o en la decisión de irse al monte a hacerse "auténticos" revolucionarios, mantenían una desconfianza hacia el estudiantado. Tal y como se mencionó para el caso del ELN, los grupos maoístas más radicales, especialmente aquellos que tenían nexos con el EPL, sostenían que los universitarios a lo sumo podrían librar batallas en el terreno ideológico y cultural, pues su condición acomodada era una tara para asumirse plenamente como proletarios o como revolucionarios comprometidos. Por esta razón, los grupos maoístas radicales llamaban la atención para que los estudiantes no usurparan el papel histórico del campesinado y de los obreros, únicas clases que podían y debían hacer la revolución socialista.

En tal orden de prioridades revolucionarias, criticaban los actos violentos protagonizados por algunos universitarios, tildados de simple "propaganda armada". A estos personajes y grupos, algún sector del maoísmo los acusó de haberse "degenerado en el anarquismo y ser inhábiles para la lucha revolucionaria. Son un grupo de resentidos y enfermos". Una carta escrita en 1969 por integrantes del EPL a los compañeros estudiantes, evidencia esta concepción guerrillera del estudiantado; eso sí, no perdieron la oportunidad para invitarlos a que dieran el paso decisivo hacia la verdadera lucha revolucionaria ${ }^{49}$. Respecto a este llamado a empuñar las armas, según ciertos analistas del tema, cuando no se descalificaba la lucha estudiantil por tenue, los grupos que conformaban la izquierda universitaria se daban a la tarea de ejercitar la antropofagia con sus similares, procurando erigirse en portadores de la única verdad proveniente de los evangelios marxistas ${ }^{50}$.

La carencia de una organización gremial de carácter nacional facilitó el predominio de los grupos de izquierda en el interior del movimiento y de la protesta estudiantil a partir de los años setenta. La dependencia de estructuras partidistas políticas externas a la dinámica universitaria, las cuales solo concebían a la universidad como una cantera proveedora de cuadros revolucionarios, también facilitó el ingreso de varios jóvenes a la lucha armada. Por otro lado, la fuerte ideologización que experimentaron los jóvenes de la época, matizada con la tradición de una cultura política autoritaria, permite entender que el compromiso político de esa generación arraigó una profunda desconfianza en la democracia, el Estado y a la vez, una fascinación por el poder de las armas. Ahora, ¿qué tiene que ver esta reconstrucción de los años sesenta y setenta con los hechos descritos en la primera parte de este artículo?

www.scribd.com/full/52353492?access_key=key-1dr9ayhki3z5ovz7cq7m, consultado (10/11/2011); JUVENTUD PATRIÓTICA, “¡Viva la gloriosa lucha estudiantil por una cultura nacional, científica y de masas!", http:/www.scribd.com/full/52353496?access_key=key-2ovx9qpazt7tj0nl6w6f, consultado el 16 de octubre de 2011 y, "Gran lucha revolucionaria de la juventud", http:/www.scribd.com/ full/52353476?access_key=key-21yg4fklb11ae00auk51, consultado (04/10/2011).

49 EJÉRCITO POPULAR DE LIBERACIÓN, “Algunos problemas de actualidad”, en PUIG, Julio y ZULUAGA, Olga (Comp.), Documentos teóricos internos al movimiento..., pp. 12-17.

${ }^{50}$ GRUPO MARXISTA LENINISTA DE ANTIOQUIA, "El movimiento estudiantil y la nueva democracia", en, PUIG, Julio y ZULUAGA, Olga (Comp.), Documentos teóricos internos al movimiento..., p. 216. 


\section{Corolario}

Luego de la segunda mitad de los años setenta, la movilización estudiantil experimentó un reflujo del que quizá no se haya recuperado sino hasta la coyuntura del año 2011. A pesar de que los factores que explican esta situación no han sido objeto de una investigación sistemática, podemos enumerar, a manera de hipótesis, los siguientes: la inexistencia de una organización nacional que aglutinara las diferentes agrupaciones políticas, el fin de la utopía socialista impactó en la ideologización de la dinámica política universitaria y la criminalización y represión por parte de fuerzas oficiales y paraestatales de las que fueron objeto desde los años ochenta. A ello se sumó una nueva política educativa que restó importancia a la universidad pública colombiana como epicentro del saber y la renovación de las elites sociales y políticas, a favor de una concepción de la educación como servicio con limitaciones presupuestales. La situación de la protesta universitaria en las últimas décadas reclama prontas investigaciones, puesto que, pese a la despolitización de los jóvenes, la reivindicación en algunos sectores de las vías de hecho e incluso de la lucha armada como forma de acción, tiene presencia en ciertos momentos de agitación y movilización ${ }^{51}$.

Por otro lado, a mediados del año 2011 el profesor Medófilo Medina, historiador y exmiembro del PCC, envió una carta al entonces Comandante en Jefe de las FARC-EP, Guillermo León Sáenz, más conocido como “Alfonso Cano". Además de la novedad del recurso de una carta pública, académica y política pero con un tono personal que pretendía sacar del ostracismo el tema de la posibilidad de dialogar con la guerrilla, el contenido de la misiva puso de presente un tema relevante para esta reflexión. El dato tiene que ver con el origen universitario del máximo comandante de las FARCEP luego de la muerte de Pedro Antonio Marín. Medina recuerda que conoció a Cano cuando este ingresaba a la Universidad Nacional de Colombia a cursar estudios de Antropología, mientras aquel ya estaba de salida. Algo similar comentó de su relación con "Iván Márquez", "Pablo Catatumbo" y "Andrés París", actuales comandantes de la guerrilla, y miembros del equipo negociador que se encuentra en La Habana. El mismo Medina les recordó explícitamente su condición originaria: “[...] en efecto, Ustedes fueron gente de estudio y dirigentes políticos urbanos antes de convertirse en cuadros militares" $"$.

La publicación de la carta de Medófilo Medina y la respuesta de Cano difundida en el portal www.lasillavacia.com, se dio varios meses antes que la opinión pública supiera que el gobierno nacional adelantaba conversaciones con las FARC-EP. Con la muerte de Cano en combate, el debate que suscitó en el país la sucesión en la jefatura de la guerrilla, desató una serie de especulaciones por el perfil del nuevo comandante

\footnotetext{
${ }^{51}$ Uno de los pocos trabajos que ha reflexionado sobre las décadas más recientes de la movilización y la protesta universitaria es el de: COTE RODRÍGUEZ, Jorge, "Más allá del 16 de mayo de 1984: Protesta estudiantil en Colombia, 1975-1984", en Controversia, No. 197, diciembre de 2011, pp. 271-306.

${ }^{52}$ Carta de Medófilo Medina, a Alfonso Cano, Bogotá, 11 de julio de 2011, http://www.razonpublica. com/index.php/conflicto-drogas-y-paz-temas-30/2213-carta-abierta-a-alfonso-cano.html, consultado (20/11/2012).
} 
fariano, toda vez que los medios suponen una inclinación mayor por el diálogo en los jefes guerrilleros que tuvieron experiencias de militancia política juvenil urbana, a diferencia de los "troperos" de origen rural como Jorge Briceño Suárez.

La formación como médico de Rodrigo Londoño Echeverry, alias Timochenko, o la militancia política de Andrés París o Iván Márquez en la Juventud Comunista en los años setenta y ochenta ${ }^{53}$, por citar tres nombres, obliga a la comunidad en general y a los académicos en particular, a aportar pistas sobre el conflicto colombiano. La vinculación a temprana edad a las filas de la JUCO, el contexto de represión generado por las fuerzas de derecha del país en los años ochenta que desató la guerra sucia, el genocidio político contra la Unión Patriótica y el reflujo de la movilización estudiantil masiva, son variables que llevaron a esta nueva generación a irse para el monte, algunos de cuyos miembros se graduaron en universidades de la antigua Unión Soviética.

En una situación similar, y acorde a la tradición que dio origen al grupo insurgente, gran parte del Comando Central del ELN también pasó por las aulas universitarias de la UIS. Las comandancias guerrilleras de nuestros días son herederas de las formas que tuvieron algunos jóvenes de la generación de los años sesenta para asumir la política ${ }^{54}$. Aunque se sabe que varios de los jefes subversivos vivieron una experiencia universitaria, lo que interesa destacar es la manera como un sector estudiantil de la universidad construyó hace tres o cuatro décadas un modo de asumir la oposición al sistema político, económico y social. La desconfianza hacia la democracia o la pretensión de resguardar los purismos ideológicos en el marco de unas nuevas condiciones históricas - tales como el fin del socialismo históricamente existente- la potenciación hasta límites insospechados de los procesos globalizadores o la profundización y crisis del neoliberalismo, han de llevar a redimensionar la comprensión del conflicto colombiano.

Aunque la reflexión sobre los intentos de paz en el país no ha sido persistente ${ }^{55}$, lo cierto es que los estudiantes universitarios no han jugado un papel significativo en ellos, más allá de la cacareada y poco conocida participación en el movimiento de la “séptima papeleta” y el proceso constituyente de 1990. El declive de la organización

\footnotetext{
53 Para el caso del máximo comandante de las FARC-EP, se puede consultar el siguiente perfil: LASILLAVACIA, "Rodrigo Londoño Echeverri", en http://lasillavacia.com/quienesquien/perfilquien/ rodrigo-londono-echeverry, consultado (21/11/2012).

${ }^{54}$ Si bien Nicolás Rodríguez Bautista se involucró en el primer núcleo del ELN que se asentó en la zona rural de San Vicente de Chucurí como un joven de extracción totalmente rural, llegó a asumir la comandancia militar de la organización que ejerce hasta el día de hoy. El resto del Comando Central ha estado vinculado a la vida universitaria, como por ejemplo, el caso de Erlington de Jesús Chamorro, conocido como "Antonio García", quien estudió dos años de Ingeniería Electrónica en la UIS para luego pasar a la vida clandestina y convertirse en el jefe político de esta guerrilla. En el mismo sentido, Israel Ramírez Pineda, alias "Pablo Beltrán" es ingeniero de petróleos de la misma universidad. Ambos hacen parte del Comando Central. Ver: REVISTA SEMANA, "El lado político de Antonio García”, http://www.semana.com/nacion/lado-politicoantonio-garcia/94088-3.aspx, consultado (30/11/2012); REVISTA SEMANA, Protagonistas. ELN, http:// www.semana.com/multimedia/md_19/protagonistas.swf, consultado (01/12/2012).

55 PALACIOS, Marco, Violencia pública en Colombia 1958-2010, pp. 137-183. CEPEDA ULLOA, Fernando, Haciendo paz: reflexiones y perspectivas del proceso de paz en Colombia, Bogotá, El Áncora, 2001.
} 
estudiantil desde finales de los años ochenta, que no alcanzó el nivel de reconocimiento de las décadas anteriores, puede llevar a las generaciones actuales a no pensar en su papel frente a la posibilidad de paz. La emergencia de culturas juveniles y otras formas de expresión de lo político deben ser asumidas por los analistas y quienes toman las decisiones del Estado en tiempos de posconflicto, especialmente por la situación potencial de desmovilización y reinserción de jóvenes militantes de las organizaciones guerrilleras.

A pesar de la simpatía que en determinados grupos políticos estudiantiles despertó la lucha armada como la forma más contundente de compromiso revolucionario, los vasos comunicantes entre insurgencia y activismo estudiantil han sido asumidos por personas aisladas. Actualmente, medios de comunicación y autoridades conciben sin mayores reservas la existencia de una estrecha relación entre estudiantes y guerrillas, trasponiendo la imagen de los años sesenta y setenta a un presente que ha mutado en muchos órdenes. Sin desconocer los problemas estructurales del sistema político colombiano y la ausencia de explicaciones sobre el conflicto de las últimas décadas, es necesario volver la mirada hacia dichas décadas en busca de nuevas claves interpretativas de la movilización estudiantil reciente. Consideramos que los titulares sobre la infiltración de la subversión en las universidades, divulgados por los medios, en el fondo reflejan la urgencia de una historia social y cultural de lo político que estime, entre otros problemas, el lugar de las clases medias en la configuración de la sociedad colombiana, los múltiples procesos de construcción de las identidades juveniles, sus expresiones organizativas y sus apuestas por transformar el orden existente $^{56}$.

\section{Fuentes}

\section{Fuentes primarias}

\section{Documentación primaria impresa}

TORRES RESTREPO, Camilo, Escritos escogidos 1966-1986, Tomo II, Bogotá, Cimarrón Editores, 1986.

\section{Entrevistas}

Entrevista a ARENAS REYES, Daniel, Bogotá, abril 3 de 2003.

Entrevista a BARRAGÁN ARENAS, Ítalo, Bucaramanga, marzo 18 de 2003.

Entrevista a OLARTE PERALTA, Mario, Bucaramanga, noviembre 10 de 1999.

\footnotetext{
${ }^{56}$ En plena movilización estudiantil contra la reforma a la Ley 30 de 1992 que regula todo lo relacionado con la educación superior en el país, se desató un debate sobre la posible infiltración de las guerrillas en las universidades. Para recordarlo se puede consultar: "La guerrilla en las universidades", en El Espectador, Bogotá, 3 de agosto de 2011, http://www.elespectador.com/noticias/wikileaks/articulo-289093-guerrillauniversidades, consultado $(02 / 12 / 2012)$.
} 


\section{Fuentes secundarias}

\section{Libros}

ACEVEDO TARAZONA, Álvaro, Modernización, conflicto y violencia en la universidad en Colombia: AUDESA, 1953-1984, Bucaramanga, UIS, 2004.

ARCHILA, Mauricio, Idas y venidas, vueltas y revueltas: protesta social en Colombia 1958-1990, Bogotá, ICANH-CINEP, 2003.

ARENAS REYES, Jaime, La guerrilla por dentro: análisis del ELN colombiano, Bogotá, Tercer Mundo, 1971.

ARREGI, Ión, "El cura Pérez": los sueños intactos, Madrid, Tercera PrensaHirugarren Prentsa, 1998.

AYAlA DIAGO, César Augusto, Resistencia y oposición al establecimiento del Frente Nacional: los orígenes de la Alianza Nacional Popular, ANAPO. Colombia, 1953-1964, Bogotá, Universidad Nacional de Colombia, 1996.

BRODERICK, Walter, Camilo Torres: el cura guerrillero, Bogotá, Círculo de Lectores, 1977.

CALVO OCAMPO, Fabiola, EPL: diez hombres, un ejército, una historia, Bogotá, ECOE, 1985.

CASTRO CAYCEDO, Germán, Del ELN al M-19: once años de lucha guerrillera, Bogotá, Carlos Valencia Editores, 1980.

CEPEDA ULLOA, Fernando, Haciendo paz: reflexiones y perspectivas del proceso de paz en Colombia, Bogotá, El Áncora, 2001.

CLAUX CLARRIQUIRY, Inés, La búsqueda: testimonio de Leonor Esguerra, Medellín, Pregón, 2001.

GÓMEZ GARCÍA, Juan Guillermo, Cultura intelectual de resistencia: contribución a la historia del "libro de izquierda". Medellín en los años setenta, Bogotá, Desde Abajo-Colciencias-Universidad de Antioquia, 2005.

HERRERA, Vianney y TRUJILLO, Leonor, Movimiento estudiantil-Universidad del Valle-1971: como fuerza social y su influencia histórica, Cali, Universidad del Valle, 1993.

LARA PARADA, Ricardo, El guerrillero y el político: conversación con Óscar Castaño, Bogotá, Oveja Negra, 1984. 
Entre la movilización estudiantil y la lucha armada en Colombia. De utopías y diálogos de Paz

LE BOT, Ivón, Educación e ideología en Colombia, Bogotá, La Carreta, 1985.

LÓPEZ, Luis y ZIFF, Trisha, Chevolution, México, 2008.

PALACIOS, Marco, Entre la legitimidad y la violencia: Colombia 1875-1994, Bogotá, Norma, 2003.

PALACIOS, Marco, Violencia pública en Colombia 1958-2010, Bogotá, Fondo de Cultura Económica, 2012.

PÉCAUT, Daniel, Crónica de cuatro décadas de política colombiana, Bogotá, Norma, 2006.

PÉCAUT, Daniel, Las FARC: ¿una guerrilla sin fin o sin fines?, Bogotá, Norma, 2008.

PIZARRO LEONGÓMEZ, Eduardo, Las FARC (1949-2011): de guerrilla campesina a máquina de guerra, Bogotá, Norma, 2011.

RESTREPO, Javier Darío, La revolución de las sotanas: Golconda 25 años después, Bogotá, Planeta, 1995.

RUÍZ MONTEALEGRE, Manuel, Sueños y realidades: procesos de organización estudiantil 1954-1966, Bogotá, Universidad Nacional de Colombia, 2002.

VALVERDE, Umberto, Colombia: tres vías a la revolución, Bogotá, Círculo Rojo Editores, 1973.

VARGAS, Alejo, Politica y armas al inicio del Frente Nacional, Bogotá, Universidad Nacional de Colombia, 1996.

VARGAS VELÁSQUEZ, Alejo, Colonización y conflicto armado: Magdalena Medio Santandereano, Bogotá, CINEP, 1992.

VILLANUEVA, Orlando, Camilo: acción y Utopía, Bogotá, Universidad Nacional de Colombia, 1995.

VILLARRAGA, Álvaro, PLAZAS, Nelson, Para reconstruir los sueños: una historia del EPL, Bogotá, Fundación Progresar, 1994.

\section{Capítulos de libros}

ARENAS REYES, Jaime, "Palabras del señor Jaime Arenas Reyes, estudiante de la Universidad Industrial de Santander 1964", en BARRIENTOS ARANGO, José, La Asociación Colombiana de Universidades, 25 años de historia (1958-1983), Bogotá, Gráficas Carmán, 1983, pp. 147-153. 
CAICEDO TURRIAGO, Jaime, "Movimiento juvenil, movimiento estudiantil y unidad popular", en PUIG, Julio y ZULUAGA, Olga (Comps.), Documentos teóricos internos al movimiento estudiantil 1971, Medellín, Universidad de Antioquia, 1974, pp. 235-236.

CHILD, Jorge, "El MRL", en GALLÓN, Gustavo y BETANCUR, Mónica, Entre movimientos y caudillos: 50 años de bipartidismo, izquierda y alternativas populares en Colombia, Bogotá, CINEP-CEREC, 1989, pp. 68-90.

COTE RODRÍGUEZ, Jorge, "El movimiento estudiantil de 1971: entre la homogeneidad y la heterogeneidad", en ARCHILA, Mauricio, Una historia inconclusa: izquierdas políticas y sociales en Colombia, Bogotá, CINEP, 2009, pp. 413-462.

EJÉRCITO POPULAR DE LIBERACIÓN, “Algunos problemas de actualidad”, en PUIG, Julio y ZULUAGA, Olga (Comp.), Documentos teóricos internos al movimiento estudiantil 1971, Medellín, Universidad de Antioquia, 1974, pp. 12-17.

GRUPO MARXISTA LENINISTA DE ANTIOQUIA, "El movimiento estudiantil y la nueva democracia”, en PUIG, Julio y ZULUAGA, Olga (Comps.), Documentos teóricos internos al movimiento estudiantil 1971, Medellín, Universidad de Antioquia, 1974 , pp. 216.

LEAL BUITRAGO, Francisco, "La participación política de la juventud universitaria como expresión de clase”, en CÁRDENAS, Martha y DÍAZ URIBE, Alberto (Eds.), Juventud y política en Colombia, Bogotá, FESCOL, 1984.

MOLANO, Frank, "La izquierda maoísta colombiana: organizaciones y mentalidades en la década de 1970”, en ACUÑA RODRÍGUEZ, Olga Yanet y GUERRERO BARÓN, Javier (Comp.), Para reescribir el siglo XX: memoria, insurgencia, paramilitarismo y narcotráfico, Medellín, La Carreta-UPTC, 2011.

POSADA, Leonardo, "Constancia ante el Comité de Solidaridad", en PUIG, Julio, ZULUAGA, Olga (Comp.), Documentos teóricos internos al movimiento estudiantil 1971, Medellín, Universidad de Antioquia, 1974, pp. 53-54.

SANCHO LARRAÑAGA, Roberto, "Discurso ideológico y religión política en la izquierda revolucionaria: reconfiguración de lo sagrado en los años sesenta del siglo XX”, en ACUÑA RODRÍGUEZ, Olga Yanet y GUERRERO BARÓN, Javier (Comp.), Para reescribir el siglo XX: memoria, insurgencia, paramilitarismo y narcotráfico, Medellín, La Carreta-UPTC, 2011, pp. 207-232.

SANTOS CALDERÓN, Enrique, "Prólogo. Un libro premonitorio", en ARENAS REYES, Jaime, La guerrilla por dentro, Bogotá, Intermedio, 2009.

VANEGAS USECHE, Isidro, "Las guerrillas, la democracia y el Frente Nacional", en CABALlERO ARGAEZ, Carlos, PACHÓN BUITRAGO, Mónica y POSADA 
Entre la movilización estudiantil y la lucha armada en Colombia. De utopías y diálogos de Paz

CARBÓ, Eduardo (Comp.), Cincuenta años de regreso a la democracia: nuevas miradas a la relevancia histórica del Frente Nacional, Bogotá, Uniandes, 2012, pp. 187-203.

\section{Artículos}

ACEVEDO TARAZONA, Álvaro, "La marcha de los estudiantes de la UIS, 1964: símbolo del movimiento estudiantil colombiano", en Revista Historia de la Educación Colombiana, No. 12, Pasto, Universidad de Nariño, 2009.

ARCHILA, Mauricio, "El maoísmo en Colombia: la enfermedad juvenil del marxismo-leninismo", en Controversia, No. 190, Bogotá, CINEP, 2008, pp. 156-158.

ARCHILA, Mauricio, "El movimiento estudiantil en Colombia: una mirada histórica", en Revista del Observatorio Social de América Latina, No. 31, Buenos Aires, Clacso, 2012, pp. 78-84.

AYALA DIAGO, César, "El origen del MRL (1957-1960) y su conversión en disidencia radical del liberalismo colombiano", en Anuario de Historia Social y de la Cultura, No. 22, Bogotá, Universidad Nacional de Colombia, 1995, pp. 95-121.

COTE RODRÍGUEZ, Jorge, "Más allá del 16 de mayo de 1984: Protesta estudiantil en Colombia, 1975-1984" en Controversia, No. 197, diciembre de 2011, pp. 271-306.

DÍAZ JARAMILLO, José Abelardo, "Del liberalismo al maoísmo: encuentros y desencuentros políticos en Francisco Mosquera Sánchez, 1958-1969”, en Anuario Colombiano de Historia Social y de la Cultura, Vol. 38, Bogotá, Universidad Nacional de Colombia, 2000, pp. 141-176.

DÍAZ JARAMILLO, José Abelardo, "Juventud, nueva izquierda y revolución en Colombia: Antonio Larrota González", en Controversia, No. 194, Bogotá, CINEP, 2010, pp. 265-291.

DÍAZ JARAMILLO, José Abelardo, "El 8 de junio y las disputas por la memoria, 1929-1954”, en Historia y Sociedad, No. 22, Medellín, Universidad Nacional de Colombia, 2012, pp. 157-189.

MORENO DURÁN, R.H, "La memoria irreconciliable de los justos: la Universidad Nacional en la década de los 60", en Análisis Político, No. 7, 1989, pp. 77-87.

\section{Publicaciones en internet}

Carta de Medófilo Medina, a Alfonso Cano, Bogotá, 11 de julio de 2011, http: //www. razonpublica.com/index.php/conflicto-drogas-y-paz-temas-30/2213-carta-abierta-aalfonso-cano.html, consultado (20/11/2012).

"Con 300 'papas bomba', los 7 capturados en Lebrija querían provocar disturbios en la UIS”, en Vanguardia Liberal, Bucaramanga, 28 de septiembre de 2012, http: 
//www.vanguardia.com/judicial/176343-con-300-papas-bomba-los-7-capturados-enlebrija-querian-provocar-disturbios-en-la-uis, consultado (21/11/2012).

"Dos estudiantes resultaron mutilados en protestas en la UPTC de Tunja", en El Tiempo, Bogotá, 20 de marzo de 2012, http:/www.eltiempo.com/archivo/documento/ CMS-11391147, consultado (19/11/2012).

"Estudiantes muertos en Suba estarían preparando atentado en Festival", en El Tiempo, Bogotá, 26 de abril de 2012, http: //www.eltiempo.com/colombia/ bogota/ARTICULO-WEB-NEW_NOTA_INTERIOR-11658122.html, consultado $(18 / 11 / 2012)$.

JUVENTUD PATRIÓTICA, “Gran lucha revolucionaria de la juventud”, http: //www. scribd.com/full/52353476?access_key=key-21yg4fklb11ae00auk51, consultado $(04 / 10 / 2011)$.

JUVENTUD PATRIÓTICA, “¡Viva la gloriosa lucha estudiantil por una cultura nacional, científica y de masas!", http: //www.scribd.com/full/52353496?access key=key-2ovx9qpazt7tj0nl6w6f, consultado (16/10/2011).

"La guerrilla en las universidades", en El Espectador, Bogotá, 3 de agosto de 2011, http: //www.elespectador.com/noticias/wikileaks/articulo-289093-guerrillauniversidades, consultado (02/12/2012).

LASILLAVACIA, "Rodrigo Londoño Echeverri”, en http: //lasillavacia.com/ quienesquien/perfilquien/rodrigo-londono-echeverry, consultado (21/11/2012).

MINISTERIO DE EDUCACIÓN NACIONAL, http://www.mineducacion.gov.co/ observatorio/1722/article-303244.htm, consultado (19/11/2012).

"Muere estudiante por explosión en marcha estudiantil de Cali", en El Espectador, Bogotá, 12 de octubre de 2011, http:/www.elespectador.com/noticias/nacional/ articulo-305037-un-muerto-marcha-estudiantil-cali, consultado (16/11/2012).

"Murió estudiante que había resultado herido en la UPTC de Tunja", en El Tiempo, Bogotá, 22 de marzo de 2012, http://www.eltiempo.com/archivo/documento/CMS11405961, consultado (19/11/2012).

"Murió estudiante tras explosión en la UPTC", en El Tiempo, Bogotá, 23 de marzo de 2012, http://www.eltiempo.com/archivo/documento/CMS-11411041, consultado (20/11/2012).

“QQuiénes son los tres estudiantes muertos tras explosión accidental en el noroccidente de Bogotá?", 26 de marzo de 2012. Http: //www.caracol.com. $\mathrm{co} /$ noticias/bogota/quienes-son-los-tres-estudiantes-muertos-tras-explosionaccidental-en-el-noroccidente-de-bogota/20120326/nota/1660284.aspx, consultado $(18 / 11 / 2012)$ 
REVISTA SEMANA, “El lado político de Antonio García”, http://www.semana.com/ nacion/lado-politico-antonio-garcia/94088-3.aspx, consultado (30/11/2012).

REVISTA SEMANA, "Protagonistas. ELN", http://www.semana.com/multimedia/ md_19/ protagonistas.swf, consultado (01/12/2012).

TORRES, Marcelo, “Discurso de Marcelo Torres ante el Consejo Nacional de Rectores", http://www.scribd.com/full/52353492?access_key=key-1dr9ayhki3z5ovz7cq7m, consultado $(10 / 11 / 2011)$.

"Tres jóvenes universitarios murieron mientras manipulaban explosivos", en El Tiempo, Bogotá, 25 de marzo de 2012, http://www.eltiempo.com/colombia/ bogota/ARTICULO-WEB-NEW_NOTA_INTERIOR-11426321.html, consultado $(18 / 112012)$.

\section{Tesis}

DÍAZ JARAMILLO, José Abelardo, El Movimiento Obrero Estudiantil Campesino 7 de enero y los orígenes de la nueva izquierda en Colombia 1959-1969, Trabajo de grado para optar al título de Magíster en Historia, Bogotá, Universidad Nacional de Colombia, 2010.

MEDINA GALLEGO, Carlos, FARC-EP y ELN: una historia politica comparada 1958-2006, Trabajo de grado presentado para optar por el título de Doctor en Historia, Bogotá, Universidad Nacional de Colombia, 2010. 